Revista

Ibero-Americana

de Estratégıa

\title{
A GESTÃO ESTRATÉGICA EM EDUCAÇÃO E SEUS IMPACTOS NA PRESTAÇÃO DOS SERVIÇOS
}

\section{STRATEGIC MANAGEMENT IN EDUCATION AND ITS IMPACT ON SERVICE PROVISION}

\section{GESTIÓN ESTRATÉGICA EN EDUCACIÓN Y SU IMPACTO EN LA PRESTACIÓN DE SERVICIOS}

\section{Carolina Barbosa Montenegro \\ Mestre em Administração pela Universidade Potiguar - UNP \\ Professora do Curso de Administração da Universidade Potiguar \\ E-mail: carolinabmontenegro@ hotmail.com (Brasil)}

\section{Kleber Cavalcanti Nóbrega}

Doutor em Engenharia de Produção pela Escola Politécnica da Universidade de São Paulo - USP Professor do Mestrado Profissional em Administração da Universidade Potiguar E-mail: klebercn@unp.br (Brasil)

\section{Tereza Souza \\ Doutora em Administração de Empresas pela Escola de Administração de Empresas de São Paulo - EAESP/FGV \\ Coordenadora do Mestrado Profissional em Administração da Universidade Potiguar E-mail: terezasouza@unp.br (Brasil)}




\section{A GESTÃo ESTRATÉGICA EM EDUCAÇÃo E SEUS IMPACTOS NA PRESTAÇÃo DOS SERVIÇOS}

\section{RESUMO}

As constantes mudanças nos padrões de serviço afetam de maneira acentuada as escolas privadas, que oferecem serviços considerados essenciais. Esta realidade fez vigorar no cliente um novo perfil, mais criterioso, exigente e com maior poder de decisão. Os serviços são, assim, afetados pelas estratégias estabelecidas pela direção. Este artigo visa analisar como as estratégias desenvolvidas numa escola particular são refletidas na qualidade dos serviços oferecidos, na visão dos gestores. Com foco nos serviços educacionais, a formulação, desenvolvimento e controle das estratégias foram analisados com três diretores, gestores da Escola estudada. Para a condução do estudo de caso foi feito uso de coleta de dados por meio de entrevista, utilizando posteriormente a análise comparativa, revelando que a Escola estudada possui uma identidade organizacional conhecida por todos os seus colaboradores e um processo de planejamento estratégico, em nível nacional, que serve de pilar para o desenvolvimento das estratégias. Os três gestores entrevistados possuem funções diferentes, mas os resultados apontam que, mesmo atuando em atividades distintas, procuram manter sintonia em relação ao andamento das atividades escolares, dando suporte às estratégias estabelecidas. Por fim, pode-se dizer que, cada um, dentro de sua visão e responsabilidades está trabalhando estrategicamente para que os objetivos organizacionais sejam atingidos, disseminando as estratégias prioritárias, mas também buscando resolver pontualmente qualquer interferência que possa afetar o bom andamento dos planos de ação estabelecidos.

Palavras-chave: Estratégia; Gestão Estratégica; Gestão de Serviços; Gestão Escolar.

\section{STRATEGIC MANAGEMENT IN EDUCATION AND ITS IMPACT ON SERVICE PROVISION}

\section{ABSTRACT}

The constant changes in service patterns affect hardly private schools, organizations that offer services considered essential. This context promotes, in effect, a new customer profile, demanding more service quality, and making use of greater autonomy. The services are thus affected by strategies established by senior management. This article aims to analyze how the strategies developed in a private school reflect on the quality of services offered, according to managers' point of view. Focusing education services, the formulation, development and control of strategies were analyzed with three directors in one school. To conduct the case study interviews were conducted, using subsequent comparative analysis, revealing that all employees know the school organizational identity and there was a planning process strategic, performed in national level, serving as a basis for development strategies. The three interviewed managers have different functions, but the results indicate that, even working in different activities, they seek to maintain harmony on conducting school activities, providing support to existing arrangements. Finally, it can be said that, each one, within its vision and responsibilities is working strategically to achieve organizational objectives. Arrangements are made to communicate main strategies, but also seeking to solve promptly any interference that may affect the execution of established action plans.

Keywords: Strategy; Strategic Management; Service Management; School Management. 


\section{INTRODUÇÃO}

Mudanças constantes nos padrões da qualidade exigida por clientes aumentam a preocupação de gestores de empresas em relação a como atender essas demandas crescentes e complexas. Tal situação afetou sobremaneira as escolas privadas, que oferecem serviços considerados essenciais. Por outro lado, o crescimento da prática concorrencial fez vigorar no cliente um novo perfil, mais criterioso, exigente e com maior poder de decisão. Nesse sentido, as escolas estão aumentando a oferta de serviços, melhorando sua qualidade e buscando mais diferenciais competitivos, na tentativa de captar e manter os clientes.

Para Menezes (2002), o cliente passa de receptor passivo para projetista ativo. O gestor começa a perceber que não basta ter uma organização interna. É preciso ir além, reajustando a interrelação das circunstâncias que vêm acompanhando a situação e sair das fronteiras da instituição para tentar entender a sua potencialidade no mercado e seu contexto na conjuntura da sociedade na qual a escola se insere. As escolas começam a enxergar a necessidade de manter um gerenciamento considerando as relações com seus clientes, indo além do seu papel básico de apenas "educar". Diante dessa perspectiva estratégica, os diretores ampliam a visão restrita de pedagogos, abrindo o foco, atrelando estratégias empresariais, trabalhando as duas visões integradas, dando sustentação à empresa, objetivando a permanência no mercado competitivo e disputado (COLOMBO, 2005).

Segundo Marini (2003), a globalização, a abertura de mercado, a tecnologia da informação e o novo conceito de qualidade de serviços impuseram um novo ritmo à prestação de serviços, e fez nascer o perfil de um novo cliente. Assim, escolas particulares foram surpreendidas por mudanças que afetaram diretamente a sua dinâmica e resultou numa oferta maior de escolas e na demanda cada vez menor de alunos. Desse modo surgem questões como: de que forma as estratégias desenvolvidas numa escola particular são refletidas na qualidade dos serviços oferecidos na visão dos gestores?

A Escola estudada é uma unidade confessional católica, particular, que possui mais de sete décadas de serviços educacionais prestados, e possui como característica essencial a formação de famílias inteiras, chegando até cinco gerações de uma mesma família, tendo um legado de continuidade, constância e credibilidade na cidade.

O artigo está estruturado da seguinte forma: introdução, contextualizando o tema e problema de pesquisa; fundamentação teórica, tratando de estratégia de serviço e qualidade em serviços, metodologia descrevendo os procedimentos para condução da pesquisa, coleta e análise dos dados; 
resultados, enfocando os resultados alcançados e a análise, e, por fim, as considerações finais, descrevendo as conclusões do estudo e tecendo comentários finais.

\section{FUNDAMENTAÇÃO TEÓRICA}

\subsection{ESTRATÉGIA DE SERVIÇOS}

Estratégia de serviços começa com a ideia de um empreendedor e de uma necessidade não atendida (FITZSIMMONS e FITZSIMMONS, 2005). O primeiro passo para pensar e planejar os serviços é "o que" e "como" ele deve ser concebido e desenvolvido - o resultado técnico ou o desfecho do processo e a dimensão funcional do processo (GRÖNROOS, 2003).

Lovelock e Wright (2006) definem estratégia de serviços como a "razão de ser" da organização. Uma estratégia de serviço capta tudo que fornece ao cliente, definindo um caminho naquilo que irá tornar irresistível. Segundo os autores (2006), depois da definição de qual segmento de mercado a empresa deve atender, a tarefa deve seguir os seguintes passos: determinar os atributos importantes do serviço para atender e superar as expectativas dos clientes, e em quais (atributos) os concorrentes são mais vulneráveis, e os atributos do serviço a ser oferecido aos clientes, baseado na vulnerabilidade, constituem a direção estratégica geral de serviços, pois, assim, a empresa alcança e mantém uma posição competitiva no mercado. Fitzsimmons e Fitzsimmons (2005), considerando que a diversidade de empresas no setor de serviços dificulta generalizar os caminhos que levam às estratégias, apresentam um conceito geral, levando em consideração dois requisitos: a compreensão das variáveis competitivas, através das quais as empresas ganham ou perdem clientes no mercado; e os elementos estruturais e gerenciais que compõem o processo, que venham a possibilitar à empresa o domínio das variáveis competitivas.

A estratégia de serviços pode contemplar aspectos como: o estudo sobre os serviços, mercado e tecnologia da área de atuação, bem como a identificação dos clientes e o nível do serviço a ser oferecido; a análise do posicionamento da empresa no mercado e o desempenho de qualidade e produtividade; o modo como a tecnologia está sendo usada para melhorar o desempenho; o reconhecimento da missão organizacional e os valores harmonizados com os clientes; e a necessidade da empresa em conhecer melhor o cliente por todos os setores, facilitando, assim, a adequação das atividades ao seu público (NÓBREGA, 1997; ZEITHAML e BITNER, 2003; VARGO; LUSH, 2004; LOVELOCK; GUMMENSON, 2004) 


\subsubsection{ENFOQUES SOBRE ESTRATÉGIA DE SERVIÇO}

Nóbrega (1997) propõe como primeira etapa de um modelo de gestão de serviços que a estratégia de serviço seja planejada, delimitando o campo de atuação e priorizando a necessidade de adoção de um pensamento que cultue o serviço ao cliente. Para estabelecer a estratégia de serviço, a organização deve identificar precisamente o meio de proporcionar valor a esse cliente. "O que a empresa efetivamente faz por seus clientes; quem são verdadeiramente os seus clientes; qual a visão (imagem) que estes clientes têm da organização.” Estas questões são necessárias para a gestão do negócio e estabelecimento do caminho a ser seguido na prestação de serviços (ZEITHAML e BITNER, 2003; LOVELOCK; GUMMENSON, 2004; LOVELOCK; WRIGHT, 2006).

Hoffman (2002), Johnston (2002) e Lovelock e Wright (2006) focam a estratégia de serviços nos aspectos que tangem a visão geral do negócio e a missão da empresa, analisando diversos fatores que retratem o posicionamento da organização no mercado. Em contraponto a esta asserção, alguns autores dão maior ênfase às estratégias de operações como coluna central da estratégia de serviços, pois veem que a qualidade do trabalho desenvolvido no setor de operações é crucial no processo de serviços, visto que o cliente está sempre presente e interagindo, do início ao fim do processo (GIANESI e CORREA, 1996; CORREA e CAON, 2002; CONTADOR e MEIRELES, 2004). Fitzsimmons e Fitzsimmons (2005) abordam a estratégia de serviços como uma discussão dificultada pela diversidade de empresas de serviços na economia e suas diferentes relações com clientes. Mas, mesmo assim, coloca que insights estratégicos são extremamente necessários para as organizações transcenderem as fronteiras e evitarem a visão míope. A estratégia de serviços deve começar com uma visão estratégica formulada, abordando questões a respeito do mercado-alvo, do conceito de serviços, da estratégia operacional e do sistema de prestação de serviços.

Para Gianesi e Corrêa (1996), a estratégia de serviços tem como finalidade ampliar o poder de competitividade da empresa por meio de decisões tomadas na área de operações. Correa e Caon (2002) discutem a gestão das operações a partir de uma abordagem estratégica dentro das organizações de serviço. O setor de operações não é mais tratado como uma função que exige um resultado a curto prazo, sem analisar as suas interfaces com os demais departamentos. Tradicionalmente, a gestão de operações é vista como algo operacional, mas esta visão mudou muito a partir dos anos 60 , quando surgiu a necessidade da estratégia nessa função. O seu objetivo passa a ser o de garantir que os processos de produção e entrega do valor para o cliente sejam alinhados com as intenções estratégicas da empresa quanto aos mercados a que pretende servir.

Lovelock e Wright (2006), diferentemente de Correa e Caon (2002), destacam que os processos operacionais, apesar de terem sua importância, são apenas um meio, um caminho para se

Revista Ibero-Americana de Estratégia - RIAE, São Paulo, v. 9, n. 3, p. 202-223, set./dez. 2010. 
atingir um fim. Os autores (2006) frisam que a diferenciação na oferta de serviços exige um foco constante sobre os demais processos, desde a concepção até a entrega do produto principal, alcançando a excelência em todas as fases do processo.

A escola Nórdica, representada por Grönroos (2003), afirma que estratégia de serviço é de suma importância no alinhamento da empresa com sua missão, assim como a congruência dos conceitos de serviços à estratégia do negócio como um todo. De modo geral, Hoffman (2002), Grönroos (2003), Zeithaml e Bitner (2003), Fitzsimmons e Fitzsimmons (2005) e Lovelock e Wright (2006) afirmam que uma organização deve formular a sua proposta de prestação de serviços concomitantemente com o mercado-alvo que pretende alcançar e com a disponibilidade de recursos e intenção estratégica. Esta decisão deve ocorrer preferencialmente por ocasião do planejamento (NÓBREGA, 1997).

Ao ressaltar a necessidade de que todas as empresas de serviços disponham de uma estratégia clara, Johnston (2002) fortalece o pensamento de que uma estratégia de serviços fornece os quadros de referência e os modelos conceituais que permitem aos gestores identificar oportunidades para melhor planejar e desenvolver ações que visem à melhoria da capacidade competitiva da empresa por meio de uma oferta de valor superior aos clientes.

No modelo sugerido por Johnston (2002), a visão de estratégia é abrangente, apresentando cinco elementos críticos: a criação de objetivos corporativos; o entendimento do ambiente; o desenvolvimento de um conceito de serviço apropriado; a identificação de objetivos de desempenho operacional; e o desenvolvimento de uma operação adequada. Esses elementos fundamentam a estratégia competitiva e estabelecem os padrões para mudanças.

Contador e Meireles (2004) sugerem um modelo estratégico de serviços voltado para aumentar a competitividade, fundamentando-se nos preceitos de campos e armas de competição. Definem campo de competição como algo peculiar, um atrativo que interessa ao comprador, como qualidade, confiabilidade e preço de produtos e serviços. A arma é o meio que a empresa utiliza para alcançar vantagem competitiva em um campo.

As estratégias em serviços estão sempre estruturadas levando em consideração tanto o resultado pelo cliente quanto a experiência vivenciada durante a interação com a empresa (XAVIER, 2005). O fato de essas empresas fornecerem atividade considerada intangível cria um desafio específico para os gestores, pois a definição, a padronização e o controle tornam-se muito mais difícil. A dificuldade aumenta na medida em que o cliente é parte integrante do processo, de forma mais ou menos intensa (CONTADOR e MEIRELLES, 2004).

Revista Ibero-Americana de Estratégia - RIAE, São Paulo, v. 9, n. 3, p. 202-223, set./dez. 2010. 


\subsection{GESTÃo ESTRATÉGICA NA EDUCAÇÃO}

O campo da gestão tem sido pródigo em inovações, propostas de modelos e também em receitas, invadindo muitos outros domínios, como público e privado, social, político e organizacional. "A gestão tem andado tradicionalmente muito ligada ao planejamento, tornando-se este uma das principais funções do gestor, se não a principal” (ESTEVÃO, 2006, p.1). Isto se confirma quando Salerno (2006, p. 11) coloca: "dentre as mudanças que se desenrolam nos sistemas educacionais, tem-se atribuído um valor especial ao planejamento, conquanto este nem sempre fique claro para os que o executam ou dele participam”. O planejamento passou a ser uma função importante para as escolas, a partir do momento em que estas instituições passaram a ser verdadeiras empresas, necessitando de uma gestão mais efetiva. Kaufman (1992) afirma que a maior parte das reformas educacionais concentra-se nos meios, sem um exame detalhado dos fins, e que o planejamento estratégico apresenta uma maneira de integrar os dois. $\mathrm{O}$ autor ainda declara que selecionar meio (maneiras) é suficiente para tentar melhorar os padrões, mas, antes disso, é necessário chegar a um acordo quanto aos fins, pois ser estratégico é saber o que atingir, justificando o direcionamento, e então descobrir as melhores maneiras de chegar lá.

A educação, como muitos outros campos, tem atravessado muitas mudanças, tornando difícil prever o futuro. O planejamento estratégico é um meio de tentar estabelecer e manter um sentido de direcionamento, um processo por meio do qual a organização é mantida em seu curso, fazendo ajustes à medida que o contexto muda (ESTEVÃO, 2006). Segundo Meyer e Lopes (2004), o planejamento estratégico é fundamental para que as instituições possam sobreviver num cenário de tantas mudanças rápidas, competição intensa e grandes desafios. Mas, para a realização desse planejamento, há a necessidade que ele seja materializado nas diversas áreas que compõem essas instituições, como financeiro, administrativo, pedagógico, ou seja, todos os setores que compõem a escola.

Para tanto, é necessário que "os gestores desenvolvam ações que gerem integração entre o planejamento e sua implantação, entre o planejamento e o pensamento estratégico e entre pensamento e ação estratégica" (MEYER e LOPES, 2004, p. 8). Para Estevão (2006), a gestão estratégica é um processo global, que visa à eficácia, integrando o planejamento estratégico (que tem a preocupação mais voltada para a eficiência) e outros sistemas de gestão, tendo todos os gestores envolvidos no desenvolvimento e implementação estratégica.

Assim, definir e determinar qual é a situação, verificando como está a instituição de ensino, levando em conta o negócio, a missão, os princípios, a análise do ambiente em que encontra-se inserida e as competências competitivas, são tarefas fundamentais para o desenvolvimento de um 
planejamento estratégico adequado e alinhado às necessidades do público-alvo do negócio. Para Meyer e Lopes (2004), o planejamento é uma função gerencial proeminente, que projeta a organização para o futuro, preestabelecendo uma programação, em que os objetivos são formulados, as estratégias estabelecidas e os recursos disponíveis e alocados visando sua implementação. "Na prática, este processo se reveste de grande complexidade ocorrendo uma distância entre a programação estratégica e sua implementação nas instituições" (MEYER E LOPES, 2004, p. 2). Kaplan \& Norton (1997) introduziram a ideia do BSC (Balanced Scorecard) como um mecanismo para desdobrar a estratégia e potencializar a sua execução.

\subsection{O SERVIÇO E A QUALIDADE EDUCACIONAL}

Bitner, Brown e Meuter (2000) destacam que as organizações - mesmo que não sejam exclusivamente prestadoras de serviço e que fundamentam suas operações, produção e comercialização de bens - já percebem a importância dos serviços como fator de sobrevivência. Adotam estratégias de desenvolvimento e expansão da oferta de serviços lucrativos, buscando sempre se posicionar e atuar como uma empresa de serviços e não como simples fornecedora de produtos.

A atual economia se baseia predominantemente em serviços, mesmo quando o que está sendo colocado à venda seja um produto. Para Singh (2002), um cliente percebe o valor completo da empresa através de seu serviço. Lovelock e Wright (2006) abordam o serviço educacional como um serviço intangível, orientado à mente das pessoas, de entrega contínua, sem interrupções, realizado através de uma parceria entre a instituição e o cliente e que, mesmo existindo um alto contato com o cliente, é de baixa customização, tem o sentido de adaptar os produtos e processos ao gosto do cliente. Mas essa análise tem mudado com o tempo e provocado fortes discussões por causa das grandes mudanças que ocorrem e vêm ocorrendo no setor. Partindo da ideia de que o cliente é o indivíduo que recebe e utiliza o serviço em uma instituição de ensino, os usuários da educação são, além dos alunos, os pais e/ou responsáveis e a comunidade como um todo, não sendo possível restringir o serviço apenas à atividade direta da aprendizagem do aluno (BARBOSA, 2005).

O uso de novas tecnologias, a busca em modernizar as instalações, o acesso aos projetos pedagógicos, a necessidade de cobrar bons preços e a preocupação com a formação e qualificação dos sujeitos despertam o interesse das organizações de ensino para uma política educacional mais planejada, concomitantemente com as exigências do mercado, do consumo, e da competitividade.

Revista Ibero-Americana de Estratégia - RIAE, São Paulo, v. 9, n. 3, p. 202-223, set./dez. 2010. 
De forma geral, as escolas aumentaram o grau de preocupação com a avaliação/desempenho do aproveitamento escolar dos alunos e a avaliação/desempenho institucional (AFONSO, 2000). Segundo Morales e Calderón (1999), o serviço educacional não se restringe apenas à atividade de ensino. As instituições não gerenciam o "negócio serviço educacional” propriamente dito, elas fornecem serviços em todas as dimensões.

Kotler e Fox (1994) colocam os serviços educacionais como um composto de serviços, como produtos educacionais (aulas teóricas e práticas, biblioteca, laboratórios), produtos recreativos (eventos, filmes, brincadeiras), produto de crescimento pessoal (centros de orientação, conselhos), produtos curativos (postos de atendimentos a urgências de saúde) e produtos de planejamento do futuro (orientação vocacional, psicológicos).

Nesse contexto, Giacomini (1995) destaca que o conceito de serviço ampliado se adapta de maneira satisfatória aos que são oferecidos por uma instituição de ensino, pois, além do oferecimento do ensino básico (aulas, avaliações e outros), é necessário que outros serviços e bens existam para que o mesmo seja consumido de maneira plena. Para que o aluno tenha uma satisfação no desenvolvimento de suas atividades, precisa de boas instalações, apoio escolar, desenvolvimento de atividades esportivas, etc. A falta do serviço complementar inviabiliza o oferecimento do serviço central: não se pode concluir que apenas boas aulas sejam essenciais para gerar a satisfação do cliente com a escola; é necessário um conjunto de serviços para gerar esta satisfação. Além disso, o serviço educacional envolve a participação de muitas pessoas no processo: alunos, professores, coordenadores, diretores e pessoal administrativo. Lecionando uma única disciplina pode haver dois ou três professores, assim, dois alunos poderão fazer a mesma série, mas terem aula com professores diferentes. "Uma aula nunca é igual à outra" (CARVALHO e BERBEL, 2001, p. 21).

A intangibilidade do serviço educacional é facilmente percebida, pois o serviço ofertado não pode ser testado, experimentado, nem avaliado antecipadamente. Não há como o aluno testar várias escolas antes de fazer a sua escolha. Por isso, a decisão da escola adequada enfrenta muitos medos pertinentes: perda de tempo, de dinheiro, insatisfação e a quase impossibilidade de reversão, pois não há como recuperar o processo em outro estabelecimento, dado seu caráter duradouro (COLOMBO, 2004). Na hora da escolha, esse aluno vai procurar aspectos que auxiliem a tornar o serviço tangível, como instalações físicas, limpeza, preço, formação, índices de aprovação, recomendações de pessoas que já foram clientes ou conhecem o trabalho desenvolvido, e outros.

Para Bandeira (1998), há um enorme desafio na construção de indicadores afirmando que, em virtude da intangibilidade do serviço-educação, o cliente precisa experimentá-lo para verificar mais seguramente sua qualidade ou então basear-se em indicadores de qualidade indiretos, como o 
sucesso de ex-alunos em exames, as indicações e a avaliação das características institucionais no que diz respeito à credibilidade e estrutura física.

Os esforços da escola na melhoria da qualidade não são novidade, mas têm recebido uma atenção cada vez maior com o passar dos anos (PREEDY, 2006). Nas escolas, "a qualidade se faz presente quando é cuidadosamente definida, descrita e implementada conforme padrões e prescrições explícitos" (PERRENOUD, 2005, p. 81). Os sistemas educativos envolvem uma codificação desses padrões de qualidade, como: objetivos de aprendizagem, modalidades de gestão, práticas pedagógicas eficazes.

Preedy (2006) comenta que uma série de questões faz com que essas organizações busquem melhorar a qualidade de ensino - questões quanto à natureza, propósito, foco, conteúdo e controle de tentativas de melhorar a qualidade. Para o autor, os atores escolares deverão estar em condições de identificar e interpretar rapidamente os problemas emergentes e de inventar soluções apropriadas, devendo aprender a responder questões-chave: quais são, no ambiente atual, as transformações, em andamento ou previsíveis, que exigem adaptações, exigem práticas ou uma organização completamente nova? Quais as lacunas a preencher, as finalidades a reorientar?

\section{MÉTODO UTILIZADO}

Tendo este trabalho a função de caráter exploratório de estudar um fenômeno pouco conhecido, que é a utilização do planejamento estratégico em uma escola particular dirigida por religiosos, a pesquisa caracteriza-se como exploratória. Trata-se de um estudo de caso, que se justifica pelo caráter exploratório da pesquisa. Conforme Yin (2003), a opção de estudo de caso, como estratégia de pesquisa, se justifica quando o estudo focaliza o âmbito das decisões, ou seja, tenta esclarecer o motivo pelo qual as decisões foram tomadas, como foram implementadas e quais os resultados encontrados. Complementando esse pensamento, Acevedo e Nohara (2004) afirmam que pesquisa exploratória proporciona ao pesquisador maior compreensão do fenômeno que está sendo investigado, permitindo o delineamento do problema de maneira mais precisa.

Quanto à natureza do método adotado nesta pesquisa foi qualitativo em sua forma de obtenção e análise dos dados. Quando da elaboração do roteiro das entrevistas foram consideradas as variáveis relacionadas às estratégias da organização compreendidas como: planejamento estratégico (método utilizado e frequência de uso); missão; visão de futuro; valores; principais estratégias; formulação, utilização e controle da execução das estratégias; e integração da gestão pedagógica com a administrativa. As variáveis são indicadores que levam a um caminho para se 
atingir os objetivos do estudo, estabelecendo interfaces entre o modelo teórico escolhido pelo pesquisador e o método de pesquisa utilizado (MALHOTRA, 2001). As entrevistas foram compostas por doze questões elaboradas com base na literatura pertinente ao assunto. (ver quadro $1)$.

Foram realizadas entrevistas com os gestores da instituição de ensino, considerando os níveis hierárquicos, sendo abordados os três indivíduos que ocupavam os cargos diretivos compreendendo: Vice-Diretor Administrativo (G1); Vice-Diretor Educacional (G2) e Diretor Geral (G3). O tipo de entrevista escolhido permite que o entrevistado explore de maneira aprofundada o assunto, colocando pontos de vista acerca da questão.

A análise das entrevistas foi realizada tendo como referência o seu conteúdo, isto é, o pensamento das pessoas quanto aos aspectos pesquisados (BARDIN, 1994). Nessa análise foram realizadas leituras das respostas dos entrevistados, buscando identificar a coerência entre os objetivos da pesquisa e as respostas dos pesquisados.

\section{RESULTADOS DO ESTUDO: DESCRIÇÃO E ANÁLISE}

\subsection{QUANTO À IDENTIDADE ORGANIZACIONAL E AO PLANEJAMENTO ESTRATÉGICO}

Os três diretores trataram das questões voltadas para o planejamento como fator preponderante para a formulação e execução de estratégias. Foi relatado por todos que a Escola local conta com a supervisão e controle de uma mantenedora em nível nacional. Isso corrobora o posicionamento de Salerno (2006) ao comentar que, dentre as mudanças ocorridas nos processos dentro das escolas, tem-se dado um valor especial ao planejamento estratégico.

Sobre a utilização do planejamento estratégico (PE), G3, assim como G2, informou que, inicialmente, o PE foi desenvolvimento nacionalmente pela mantenedora, elaborado por uma equipe composta por membros da diretoria executiva, gerências e por um grupo de diretores de unidades de todo o país. A mantenedora elaborou o PE no intuito de que todas as escolas integrantes do sistema adotassem uma linha de ação coesa, para desenvolver o pensamento integrado e as ações ligadas ao bem comum da rede, mantendo um equilíbrio e objetivos comuns nas unidades espalhadas pelo país. Para G3 "é interessante esse planejamento nacional, pois as unidades conseguem assim unificar o pensamento da rede, a concepção, os valores e os princípios". Para os gestores, a Escola procurava, além de colocar à disposição um ensino de boa qualidade, formar o jovem de modo integral, através da religiosidade. 
G1 e G2 informaram que a unidade estava em processo de elaboração do plano local com base no plano da mantenedora. G3 comentou sobre a formulação do plano local: "agora cada unidade desenvolve as ações do PE da mantenedora a fim de dar o encaminhamento geral da rede em cada unidade". O PE local estava em elaboração, contando com a participação de todos que compõem a Escola: professores, coordenadores, dirigentes e alunos.

Como a mantenedora elaborou um PE voltado para todas as unidades, sabe-se que a Escola tinha sua identidade organizacional bem definida, sendo a missão aceita e conhecida pelos gestores. Os entrevistados, além de conhecerem a missão da Escola, conseguem relacioná-la a aspectos práticos do cotidiano. Existia uma visão de futuro nacionalmente conhecida, como também uma visão (uma meta) do que a unidade de Natal $(\mathrm{RN})$ pretendia atingir, embora ainda não houvesse sido divulgada.

Em relação à conscientização da missão por todos os colaboradores, G1 afirmou que a incorporação da identidade do negócio, para os funcionários administrativos, se deu de forma lenta e numa linguagem simples, através de reuniões, com o intuito de apresentar o plano estratégico, mostrando a todos a missão e a visão de futuro, apresentando as ações necessárias para atingir os objetivos. Já com os professores essa conscientização foi disseminada de maneira mais intensa.

Observou-se que todos os entrevistados tinham entendimento da necessidade do PE para o bom funcionamento da instituição visando, sobretudo, unificar o pensamento de toda a equipe para atingir os objetivos traçados. Este sentimento partiu inicialmente do G3, que tenta compartilhar as ações contidas no plano, por G1 disseminando as estratégias e controlando-as junto aos funcionários do setor administrativo, e por G2 que divulgava, executava e avaliava como as estratégias eram colocadas em prática pelas equipes envolvidas com o ensino propriamente dito. Todos citaram como o PE foi desenvolvido, fazendo uso da análise da matriz SWOT.

Foi exposto por G2 que "a Escola utilizou algumas iniciativas para atingir o objetivo de excelência educacional". Uma delas foi a estruturação do manual de procedimentos pedagógicos, lançado em assembleia e jornada de professores. Tal documento continha toda a filosofia, história da Escola, informações a respeito de como o educador deve proceder e pensar pedagogicamente, além dos princípios básicos do ideário e formulários, visando unificar a linguagem no trabalho do dia a dia do professor.

\subsection{QUANTO À INTEGRAÇÃO DO PEDAGÓGICO COM O ADMINISTRATIVO}

G3, por atuar na escola como o responsável pelo acompanhamento e supervisão das duas partes, administrativa e pedagógica, realizava tarefas mais estratégicas de captação de clientes, 
atendimento personalizado aos pais e professores, dentre outras atividades. Segundo G2: "O diretor geral participa ativamente nos dois setores". Uma questão descrita pelos gestores foi sobre como ocorre o relacionamento e a integração entre a gestão pedagógica e a administrativa, fato de relevância dentro do ambiente educacional, conforme Colombo (2005) e Estevão (2006) que percebem a escola hoje como uma verdadeira empresa, onde ela consiga sobreviver e enfrentar o mercado utilizando as ferramentas administrativas.

Os três gestores afirmaram que não existia uma gestão mais importante que outra (administrativa ou pedagógica) na Escola. A gestão administrativa foi considerada tão importante quanto a pedagógica. G3 afirmou que "toda a escola deve trabalhar em unidade, buscando sempre o consenso, pois na maioria das ações a serem realizadas e colocadas em prática, tanto é necessário envolver o administrativo, na parte de gerenciamento, de possibilitar a viabilidade financeira da ação, quanto na parte pedagógica, transformando a ação em ensino, proporcionando ganho de aprendizado para o aluno". G2 afirmou que "nos dias atuais, em razão do número de alunos e da quantidade de atribuições do gestor, fez-se necessário dividir os setores, administrativo e pedagógico, mas não de forma segmentada, tendo que interagir em prol da instituição". Segundo G1, na Escola, "as questões financeiras são muito importantes, não deixando de lado o foco pedagógico". Ele afirmou que "o resultado financeiro é necessário para que o trabalho pedagógico possa ser feito com qualidade".

Nessa perspectiva, a Escola era visualizada por seus gestores de forma sistêmica. Colombo (2004) aponta que, embora ainda se conserve a resistência em aceitar a legitimidade de buscar o lucro por meio da prestação de serviços educativos, percebe-se que a própria sociedade se encarregou de cobrar dos colégios privados um posicionamento empresarialmente responsável e moderno, diante de uma demanda mais criteriosa e exigente, devendo focar os dois aspectos: o educacional e o empresarial, e que apenas o equilíbrio destes levará à continuidade do sistema.

\subsection{QUANTO A CONCEITOS E PRINCIPAIS ESTRATÉGIAS DESENVOLVIDAS}

Sobre o conceito de estratégia, os gestores asseveraram que é um meio através do qual a escola consegue desenvolver seu trabalho de maneira eficaz, visando satisfazer os clientes. Gianesi e Corrêa (1996) afirmam que a estratégia de serviços tem como maior finalidade ampliar o poder de competitividade da empresa, mantendo-a atuante no mercado.

G3 definiu estratégia como "a utilização de meios disponíveis na instituição, na unidade para atingir um objetivo, uma meta". G1 e G2 acabaram utilizando a conceituação de Contador e 
Meireles (2004) que fundamenta a estratégia como armas de competição como sendo o meio que a empresa utiliza para alcançar vantagem competitiva.

Sobre as principais estratégias adotadas, o relato de G3 citou estratégias voltadas para as diversas áreas da instituição, confirmando a sua visão ampla do negócio, atuando em todos os processos. G3 relatou algumas estratégias na área de tecnologia, como a implementação do sistema P3D, software educacional em três dimensões, ferramenta utilizada para ajudar o professor, tornando a aula mais interativa, e o PC conect, sistema voltado para a realização da interação da escola com o aluno, sendo a primeira uma ação nacional e a segunda local, além da disponibilidade de internet sem fio (wireless), possibilitando o uso de laptops no colégio, liberando a necessidade do uso do laboratório de informática apenas para consultas e pesquisas. Os demais gestores não abordaram estratégias relacionadas à tecnologia educacional.

A Escola possuía uma estrutura ampla, mas de construção antiga. Para G3 "uma estratégia desenvolvida aos poucos foi a reforma do colégio, mudanças de piso em salas de aula, carteiras, lousas, etc., proporcionando maior conforto aos alunos. Além disso, houve a necessidade de adaptações, principalmente no que dizia respeito à inserção de deficientes, pois as instalações possuíam mais de cinquenta anos de uso".

Em relação à capacitação do pessoal, todos os gestores comentaram que a Escola adotou estratégias para treinar os funcionários de linha de frente visando melhorar o atendimento ao cliente, já tendo realizado algumas ações neste sentido. Conforme G1 e G3, a estratégia focada para melhorar a qualidade do atendimento a toda comunidade escolar era considerada como a principal. Para tanto, fez-se necessária a utilização de estratégias emergentes que já estavam sendo colocadas em prática através de cursos de atendimento ao cliente, ministrados aos funcionários diante das necessidades específicas de cada setor.

Outra estratégia revelada como contingencial por G3 foi a reestruturação de cargos e funções na Escola, gerando remanejamento dos profissionais que já trabalhavam na instituição para outros cargos. A mudança fez com que alguns funcionários voltassem às funções que já haviam exercido, deparando-se com novos desafios, e realizando algumas demissões e novas contratações, a fim de dinamizar o trabalho, dar unidade nos processos, e, consequentemente, reduzir os custos de folha de pagamento. Para isso, foi necessária a formação continuada, inicialmente com os gestores, depois com os funcionários que iriam ocupar as novas funções. A dificuldade inicial, citada pelo gestor, não foi perceber que as pessoas não tinham aptidão, mas sim o fato de estarem acostumadas a determinada atuação e terem que se adequar ao novo formato. G3 declarou que tal estratégia foi percebida pelos clientes, mas não chegou a criar maiores impactos no primeiro momento. A visão 
das novas funções fez com que os funcionários envolvidos no processo tivessem uma percepção holística do sistema, permitindo o mesmo à direção. Esta estratégia não foi citada pelos demais gestores, G1 e G2, que abordaram questões mais relacionadas às suas áreas de atuação.

Outro ponto mencionado por G3 foi o fato da ausência do religioso na função de direção geral. Como estratégia da rede nacional, foi instituído que o religioso voltasse a assumir o cargo, não apenas na unidade Natal, mas em todas as outras geridas por leigos. Isso se deu pela questão dos colégios serem tradicionais católicos e haver uma expectativa por parte da comunidade escolar. $\mathrm{O}$ entrevistado frisou que não se tratava de competências ou habilidades de quem dirigia, mas existia a certeza que as pessoas preferiam e viam a função da diretoria como uma forma de manter a doutrina da mantenedora mais viva e atuante. Consequentemente, como resultado, houve uma preocupação maior com a preparação religiosa dos alunos, pois, segundo G3, "a cidade é bastante tradicionalista e a população ainda é presa a certos padrões e valores”.

A Escola imbuiu-se de facilitar e dinamizar a vida dos clientes em todos os aspectos, pois segundo G2 e G3, quanto mais comodidade e agilidade o cliente tem, mais fiel ele tende a se tornar. Isso vai desde a compra do material escolar, uniforme, até o recebimento de comunicados e boletins. Por isso, a Escola implantou uma livraria e uma loja de uniformes que possibilitaram maior comodidade aos pais na compra do material escolar, como também disponibilizou o portal on-line, onde passou a ser possível retirar faturas bancárias, consultar notas, averiguar o calendário escolar, acessar comunicados, dentre outras facilidades. G1 não comentou este aspecto.

Outra estratégia citada por G1 e G3 foi buscar atender às necessidades dos alunos na área do esporte, disponibilizando um leque de possibilidades de modalidades e horários para facilitar a participação nessas atividades e para que a família pudesse se planejar melhor e fazer com que o aluno praticasse o esporte de sua preferência, no horário mais conveniente.

O projeto do sistema de avaliação da rede de escolas foi uma estratégia da mantenedora, mencionada por G2 e G3. A ferramenta pedagógica visou fazer uma avaliação contínua do processo ensino-aprendizagem, tanto das deficiências de aprendizagem do aluno, quanto das deficiências do professor. Trata-se de uma avaliação realizada nas séries que iniciam os níveis 1o e 6o do ensino fundamental e 10 ano do ensino médio. Através desse exame, os educadores conhecem o real nível dos alunos, e a partir daí podem buscar a recuperação das deficiências dos discentes, permitindo que o trabalho do professor possa ser mensurado com base no aprendizado. Além disso, o sistema dá o retorno dessa situação para os pais e responsáveis. Em relação ao foco na área administrativa, G1 fez alusão à estratégia financeira do Escola, afirmando que "a intenção é tornar as finanças mais saneadas, sem perder de foco o pedagógico, mas racionalizando melhor os custos e investimentos, 
planejar onde e como aplicar de forma mais eficaz os recursos disponíveis, dando prioridade às ações compartilhadas junto ao pedagógico e que venham gerar melhor qualidade do ensino como um todo". O atendimento de todos os funcionários, inclusive professores e coordenadores, da Escola, e a melhoria da gestão dos recursos financeiros foram citados como os dois pontos estratégicos mais importantes segundo G1, pois envolveu a participação de toda a comunidade escolar.

G1 trouxe à tona a questão da importância da clareza das informações e a credibilidade destas, tanto entre os funcionários quanto destes junto aos alunos e pais. Revelou também que a comunicação entre professores e alunos não deveria mais ser a simples transferência de informações - o educador deve ter a consciência que ele é o responsável pela transformação dessas informações em conhecimento, contribuindo assim para o enriquecimento da vida do aluno. "A intenção é fazer com que o docente seja uma mola propulsora para levar informações e seja também agente transformador do conhecimento", disse ele. Para que essa consciência fosse incorporada pelos docentes, a estratégia inicial foi o investimento na qualificação, não deixando de lado a filosofia e a religiosidade da Escola.

G1 e G2 concordaram que as estratégias, como a melhoria na comunicação, foram algo prioritário para a continuidade do trabalho. Mas G2 foi além, fazendo paralelo desta melhoria da comunicação com a necessidade de todos os membros da equipe terem clareza sobre a missão, visão e princípios da Instituição, levando isso constantemente para reuniões e momentos de compartilhamento de colaboradores. Prado (2001) afirma que, de fato, a habilidade da comunicação é fundamental para um gestor.

G2 apontou como uma estratégia essencial, no momento, tanto em nível nacional quanto local, a gestão educacional sistêmica, mas sendo subdividida em pedagógica e administrativa, sem tirar a essência dos processos. E concluiu: "acho que essa é a principal das estratégias”. Para G2, a formação continuada dos professores, objetivando a qualificação, através de videoconferência com profissionais específicos da área que atuam na gestão educacional, foi citada por todos os gestores como estratégia emergente.

No Quadro 1 é apresentada uma síntese dos principais resultados e a correspondência com os autores referenciados: 


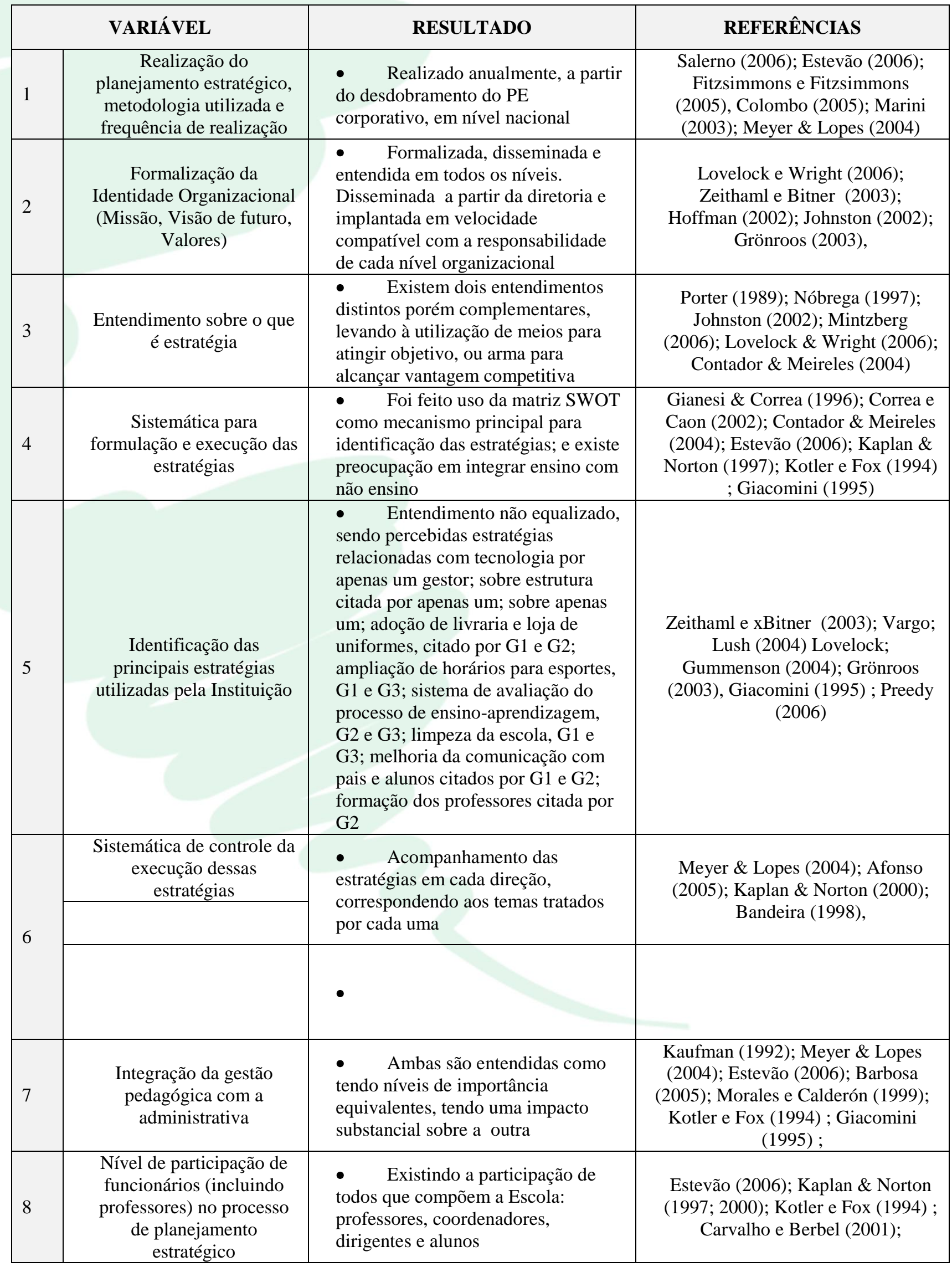

Quadro 1: Quadro resumo dos principais resultados alcançados. Fonte: Elaborado pelos autores.

Revista Ibero-Americana de Estratégia - RIAE, São Paulo, v. 9, n. 3, p. 202-223, set./dez. 2010. 


\section{CONSIDERAÇÕES FINAIS}

A partir da questão inicial, sobre a relação entre as estratégias e seu impacto nos serviços oferecidos, a presente pesquisa procurou levantar, segundo a visão dos gestores, como estes dois aspectos se relacionam, e como as estratégias estão sendo estabelecidas e monitoradas.

O estudo permitiu concluir que a Escola estudada possui estratégias claras e que são divulgadas a todos os colaboradores, sejam eles professores, coordenadores ou funcionários. $\mathrm{Na}$ percepção dos gestores, a conquista e a manutenção da qualidade dos serviços oferecidos é o alvo central dos trabalhos realizados na unidade estudada. Para eles, a principal tarefa é formar os jovens com base no ensino de qualidade, tentando sempre satisfazer os clientes nas pequenas coisas.

Percebe-se que a visão dos gestores está diretamente relacionada à função que ocupam, ou seja, o diretor geral demonstrou em suas arguições uma visão holística da Escola, comprovando a sua influência e participação tanto no setor pedagógico, relacionado diretamente ao ensino, quanto no setor administrativo, que funciona como base e suporte ao ensino. Tal visão foi confirmada pelas explanações a respeito do desenvolvimento das estratégias tecnológicas, de ensino-aprendizagem, de atendimento aos clientes, financeiras, dentre outras.

Assim, conclui-se que os gestores, mesmo sabendo da necessidade do administrativo e do pedagógico da Escola estar em sintonia, por causa da complexidade dos serviços oferecidos, separam as áreas, sobretudo nos assuntos mais operacionais, mas tentam trabalhar conjuntamente.

Como implicações para a academia, pode-se afirmar que algumas interfaces apontadas na pesquisa integram aspectos estratégicos com a qualidade dos serviços, em especial: a participação dos professores na formulação e execução das estratégias; a necessidade de integrar aspectos pedagógicos com não pedagógicos; a constatação de que as escolas, tradicional reduto de pedagogos, adota, crescentemente, práticas de administração, aumentando a percepção gerencial de professores, estejam estes em cargo apenas de ensino ou de direção.

Como implicações gerenciais, foi possível constatar a necessidade de atuação conjunta das diferentes áreas de uma escola; a necessidade de integrar professores com não professores, isto é, equipe de apoio e administrativa; que a qualidade dos serviços transcende as fronteiras da sala de aula, envolvendo infraestrutura, tecnologia, espaço físico, esportes e até mesmo questões de limpeza e higiene das instalações.

Em termos de limitações, esta pesquisa, por ser estudo de caso, não permite que se possa generalizar as conclusões para outras escolas ou instituições de educação. O intuito foi avaliar como os gestores percebem que o planejamento estratégico e a gestão estratégica influenciam a qualidade da operação nos serviços prestados. Foi possível identificar algumas relações de maior impacto.

Revista Ibero-Americana de Estratégia - RIAE, São Paulo, v. 9, n. 3, p. 202-223, set./dez. 2010. 
Outros trabalhos podem ser feitos integrando a visão dos gestores com a percepção por parte de clientes, em especial os alunos e seus pais.

\section{REFERÊNCIAS}

Acevedo, C. R., \& Nohara, J. J. (2004). Monografia do curso de administração. São Paulo: Atlas.

Afonso, A. J. (2000). Avaliação educacional: regulação e emancipação. São Paulo: Cortez.

Bandeira, M. L., Gonçalves, C. A., Veiga, R. T., \& Huertas, M. K. (1998). Avaliação da qualidade de ensino de pós-graduação: elementos para construção e validação de um instrumento de pesquisa (PP. 1-15). Anais do Encontro da Associação Nacional de Pós-Graduação e Pesquisa em Administração, 22. Rio de Janeiro: ANPAD.

Barbosa, D. F. (2005). Implementação da qualidade total na educação. Belo Horizonte: UFMG.

Bardin, L. (1994). Análise de conteúdo. Lisboa: Edições 70.

Bitner, M. J., Brown, S. W., \& Meuter, M. L. (2000). Technology infusion in service encounters. Journal of Academy of Marketing Science, 28(1), 138-149.

Carvalho, B. G., \& Berbel, M. (2001). Marketing educacional: como manter e conquistar mais alunos (2a ed.). São Paulo: Alabama.

Colombo, S. S. (2005). Marketing educacional em ação: estratégias e ferramentas. Porto Alegre: Artmed.

Colombo, S. S. (Org.). (2004). Gestão educacional: uma nova visão. Porto Alegre: Artmed.

Contador, J. C., \& Meireles, J. L. (2004). Modelo de campos e armas de competição [CD-ROM]. Anais do Encontro Nacional de Engenharia de Produção, 24. Rio de Janeiro: ABEPRO.

Correa, H. L., \& Caon, M. (2002). Gestão de serviços: lucratividade por meio de operações e de satisfação dos clientes. São Paulo: Atlas.

Estevão, C. (2006). Gestão estratégica nas escolas (Cadernos de Organização e Gestão Curricular). Lisboa: Instituto de Inovação Educacional. 
Fitzsimmons, J. A., \& Fitzsimmons M, J. (2005). Administração de serviços: operações, estratégia e tecnologia da informação (4a ed.). Porto Alegre: Bookman.

Giacomini, G. (1995). Paradigmas do marketing educacional no Brasil: comunicação para o mercado. São Paulo: EDICON.

Gianesi, H. L., \& Corrêa, I. G N. (1996). Administração estratégica de serviços. São Paulo: Atlas.

Grönroos, C. (2003). Marketing: gerenciamento e serviços. Rio de Janeiro: Elsevier.

Hoffman, K. D. (2002). Princípios do marketing de serviços: conceitos, estratégias e casos. São Paulo: Pioneira.

Johnston, R. (2002). Administração de operações de serviço. São Paulo: Atlas.

Kaplan, R. S., \& Norton, D. P. (2000). Organização orientada para a estratégia. Rio de Janeiro: Campus.

Kaplan, R. S., \& Norton, D. P. (1997). A estratégia em ação: balanced sorecard. Rio de Janeiro: Campus.

Kaufman, R. (1992). Mapping educational success: strategic thinking and planning for school administrator. New Bury Park, CA: Corwing Press.

Kotler, P., \& Fox, K. (1994). Marketing estratégico para instituições educacionais. São Paulo: Atlas.

Lovelock, C., \& Gummenson, E. (2004). Whither services marketing? In search of a new paradigm and fresh perspectives. Journal of Service Research, 7(1), 20-41.

Lovelock, C., \& Wright, L. (2006). Serviços, marketing e gestão (C. K. Moreira, Trad.). São Paulo: Saraiva.-

Malhotra, N. K. (2001). Pesquisa em marketing: uma orientação aplicada (3a ed.). Porto Alegre: Bookman.

Marini, A. L. C. (2003). Caminhos possíveis para a qualidade de ensino [CD-ROM]. Anais do Encontro Nacional de Engenharia da Produção, 23. Rio de Janeiro: ABEPRO.

Menezes, J. M. (2002). Administração estratégica como ferramenta de gestão escolar. Dissertação de Mestrado, Programa de Pós-Graduação em Engenharia de Produção, Universidade Federal de Santa Catarina, Florianópolis. 
Meyer Junior, V., \& Lopes, M. C.(2004). Planejamento e estratégia: um estudo de caso em universidades brasileiras [CD-ROM]. Anais do Congresso da Sociedade Latino-Americana de Estratégia, 12. Itajaí: Univali.

Mintzberg, H., Lampel, J., Quinn, J. B., \& Ghoshal, S.(2006). O processo da estratégia: conceitos, contextos e casos selecionados (L. O. Rocha, Trad.) (4a ed.). Porto Alegre: Bookman.

Morales, M., \& Calderón, L. F. (1999). Assessing service quality in schools of business: dimensions of service in continuing professional education (CPE) (pp. 524-536). Proceedings of the Annual Conference of the Business Association of Latin American Studies, 1999. Tampa: University of Tampa Press.

Nóbrega, K. C. (1997). Gestão da qualidade em serviços. Tese de Doutorado, Escola Politécnica, Universidade de São Paulo, São Paulo.

Perrenoud, P. (2005). A escola de A a Z: 26 maneiras de repensar a educação. São Paulo: Artmed.

Porter, M. E. (1989). Vantagem competitiva: criando e sustentando um desempenho superior (E. M. P. Braga, Trad.). Rio de Janeiro: Elvesier.

Prado, M. G. O., \& Prado, D. M. (2001). O administrador escolar: visão e esclarecimentos. Revista Interação, 3(3), 31-35.

Preedy, M. (2006). Gestão em educação: estratégias, qualidade e recursos. Porto Alegre: Artmed.

Salerno, S. C. E. K. (2006). Administração gerencial ou gestão administrativa? Foco no planejamento educacional. Tese de Doutorado, Faculdade de Educação, Universidade Estadual de Campinas, Campinas.

Singh, J. (2002). Performance productivity and quality of frontline employees in service organizations. Journal of Marketing, 64(2), 15-35.

Vargo, S. L., \& Lusch, R. F. (2004). Evolving to a new dominant logic for marketing. Journal of Marketing, 68, 1-17.

Xavier, F. M. (2005). A formulação da estratégia de operações como fator de melhoria da competitividade no varejo. Tese de Doutorado, Programa de Pós-Graduação em Engenharia da Produção, universidade Federal de Santa Catarina, Florianópolis.

Yin, R. K. Estudo de caso: planejamento e métodos (D. Grassi, Trad.) (2a ed.). Porto Alegre: Bookman.

Zeithaml, V. A., \& Bitner, M. J. O. (2003). Marketing de serviços: a empresa com foco no cliente (2a ed.). Porto Alegre: Bookman, 2003. 
Recebido: 01/08/2010

Aprovado: 13/11/2010

Revista Ibero-Americana de Estratégia - RIAE, São Paulo, v. 9, n. 3, p. 202-223, set./dez. 2010. 